
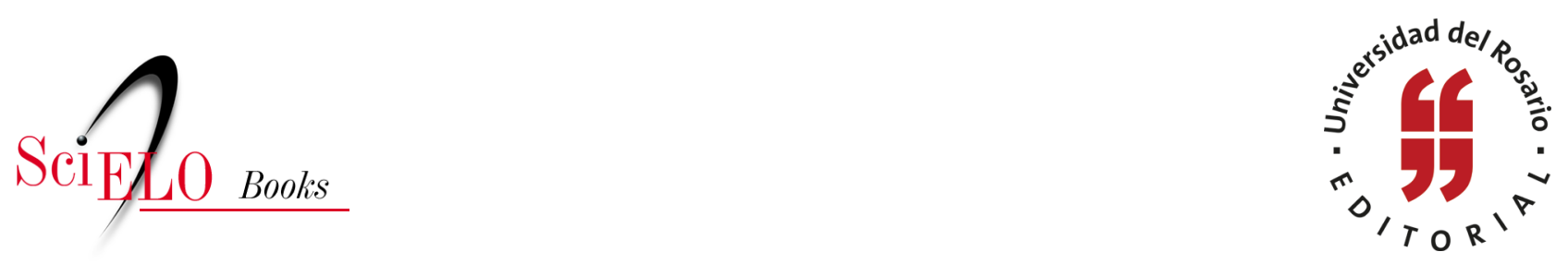

\title{
10. El tiempo / en el amor / y / sin él
}

\author{
César Augusto Tapias Hernández
}

\section{SciELO Books / SciELO Livros / SciELO Libros}

TAPIAS HERNÁNDEZ, C.A. El tiempo / en el amor / y / sin él. In: Historias de familia: Etnografía delirante sobre el amor, la violencia y las drogas [online]. Bogotá: Editorial Universidad del Rosario, 2014, pp. 41-43. Textos de ciencias humanas collection. ISBN: 978-958-738-543-4.

https://doi.org/10.7476/9789587385434.0011.

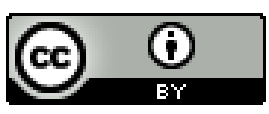

All the contents of this work, except where otherwise noted, is licensed under a Creative Commons Attribution 4.0 International license.

Todo o conteúdo deste trabalho, exceto quando houver ressalva, é publicado sob a licença Creative Commons Atribição $\underline{4.0}$.

Todo el contenido de esta obra, excepto donde se indique lo contrario, está bajo licencia de la licencia $\underline{\text { Creative }}$ Commons Reconocimento 4.0 . 


\title{
10. El tiempo / en el amor / y / sin él
}

\author{
A Homero le gustaria narrar otros dolorosos detalles que ha \\ mezclado con su profunda amargura, pero sabe que tantos \\ llorarian al oirlo y tiene piedad de ellos y los omite. \\ Raúl Gómez Jattin, Homero
}

Un día temprano por la mañana, cuando salía para el trabajo, mi tío Willi se encontró en la reja que separaba la casa de los abuelos de la calle una nota que entre líneas desmemoriadas, borradas por la infamia de los años y la rabia, le decía que él no era hijo de mi abuelo. Y él, todo lleno de rabia, fue y le dijo a la mamita un poco de cosas feas que aún hoy le parecen feas y le da hasta cierta piedra el haberlas pronunciado... Y a pesar de la pena, nunca se disculpó porque "En la casa... eso de pedir disculpas nunca se practicó. Pasaban las cosas y nadie volvía a decir nada. Normal”.

Cuentan en el barrio que mi abuela Gélica era muy celosa con el papito Fonso. Y que por eso tuvo grandes diferencias con vecinos y vecinas. Verdaderos problemas. La abuela acusaba, los acusados respondían. Considerando eso, entendió con el tiempo la nota que una mañana lo dejó abrumado. Las intenciones. Los reclamos. ¿Cómo habrán sido los reclamos en aquella época? Pasó el tiempo en casa de mi abuela y a la final eso ya no importó. Como cuando la tarde pasa a hacerse noche. Entonces imagino la calle que conducía a casa de mis abuelos, invadida de sueños, sueños sin mesura, y llenos de groserías... y a mi tío huyendo del lugar. Fugándose. Buscando amor... intentando salvarse.

De entre los hijos de la abuela, el tío Willi fue el primer afiebrado por las motos. Lo recuerdo trabajando la mensajería en su moto, una Kawasaki roja... Me parecía que volaba, rapidísimo, como toreando al viento que quería despeinarle su cabello... y colgados en el viento... dejaba besos para sus admiradoras, untados del humo azul de la gasolina quemada. Pero, de pronto como cualquier gacela, 
siempre fácil de agarrar a pesar de la carrera, la fragancia de una rosa le sedujo... El Willi enamorado terminó casado, pero al poquito tiempo, pasado el amor, el amor perdió... Se separó, siguió correteando el viento:

- Me casé con Rosa, pero ella no paraba la tomadera de trago y las fiestas con sus hermanos casi a diario... Y me iba de ella aburrido, pero volvía además humillado, porque la quería. Y llorando le decía: mañana será domingo pa' mí, mañana será domingo pa' mí... Un día, coincidieron la aburrición por ella y un buen trabajo: la opción de arrancar otra vez, entonces me abrí...

Con hija a bordo, Willi regresó a trabajar en terrenos conocidos, una agencia de viajes de un mancito-mafiosito que lo necesitaba así de pillo y de rapidísimo como se veía en su moto roja. Entonces su entusiasmo salió del taller, rompió de nuevo el viento y hasta se dejó embriagar por el aroma de una nueva flor.

De donde vivió con su nuevo amor, recuerdo que sobresalía un almacencito que se atendía por la ventana y dejaba ver mil variedades de las mercancías que pueden encontrarse en una miscelánea, cuchillas, adornos, cosméticos y unas pequeñas obras de arte que María Eugenia, la flor del nuevo aroma, pintaba con colores inventados de otros colores, paisajes realistas que adornaban cerámicas pálidas-revividas ante sus ojos... Y al fondo de la casa, resonaba una sonrisa larga, sin pena, brillante, la de Vanessa.

Era otro Willi que con el tiempo, y rodeado de margaritas, dejó las motos para mejor montarse a los carros. Así, en un auto particular o uno de servicio público, como fuera, se la pasaba buscándose las carreras de arriba abajo, y esperando con esperanza entre semáforos y cruces con glorietas, que le saliera un viaje pa'l otro lado. España o Estados Unidos... "Y no es por goma o simplemente porque todo el mundo se va. Yo no veo posibilidades de progreso aquí, pelao”.

Juliana, su hija mayor, la que tuvo con Rosa, de trece años para cuando escribía esta historia, ha querido irse a vivir con él, aburrida también de Rosa y sus rumbas; pero siendo como Rosa, según dice el mismo Willi, "No vive conmigo porque... de pronto sí me voy, no puedo dejarle esa responsabilidad a María Eugenia... ¡Mejor no, que se quede con la mamá! ¡Son iguales!”.

El viento mejoró y cuando Rosa vio que Willi no solo no regresaría, sino que tenía otro jardín... Lo buscó y no dudó en pedirle perdón, pero el Tales, orgulloso y lleno de motivos, fue inclemente, con severidad como si él fuera el destino, le fue diciendo: “¡Hoy es Domingo para mí!”. 
Queremos, dice Estanislao Zuleta (1994, citado en Gutiérrez, 2013), un mundo de seguridades y tranquilidades, amores eternos, verdades firmes, nichos seguros. "Deseamos mal". Esto es fuente continua de intolerancia y males sociales, y de la incapacidad de desarrollar nuestras propias potencialidades individuales. En la sociedad actual, cuyo seno observamos para culpar a la familia de casi todos los males... Ese ideal pedestre inevitablemente empobrece y bloquea el progreso "sin descanso" hacia "una altísima existencia" (Goethe, 2009). Deseamos no solo una buena familia, sino un buen trabajo, y que no hayan más conflictos en torno nuestro. Yo mismo mientras escribo padezco de la angustia de vivir como he podido... Pero mantengo el deseo de mejorar. Sin embargo, ante la pregunta de este gran ensayo por las relaciones entre el sujeto y la colectividad, en una sociedad por demás injusta, basada en la explotación y en la dominación de clase, recuerdo las palabras de Primo, el personaje que abre la etnografía de Bourgois (1995): "Vendiendo crack en Harlem": "Man, I don't blame where I'm at right now on nobody else but myself ", 1 pero mi lugar en medio de los demás es un lugar en medio de estructuras de poder que apenas podemos ver... La familia y nuestro lugar en ella... La lucha diaria por fuera no es solo la familia la que nos oprime... Es la sociedad que se confecciona en la familia.

1 "Pana, yo no culpo a nadie aparte de mí por la situación en la que estoy". 